\title{
Evaluation of the effect of aromatherapy in management of knee osteoarthritis patients
}

\author{
Abstract \\ Objective: The study was performed to evaluate the effectiveness of aromatherapy \\ massage in the treatment of grade two knee osteoarthritis. \\ Patients and methods: 32 cases having bilateral grade two knee osteoarthritis were \\ subjected to a massage with Lavender oil three times per week for four weeks. \\ Results: The 32 patients showed significant improvement in pain on VAS, morning \\ stiffness time and tenderness score just after the end of the sessions. \\ Conclusion: Aromatherapy is a safe and cheap tool for reducing the pain of grade two \\ knee osteoarthritis in patients. \\ Keywords: knee, osteoarthritis, aromatherapy, lavender oil, complementary \\ modalities
}

Volume II Issue 2 - 2018

\author{
Remington Zhang,' Tonya L Kerrin, ${ }^{2}$ Emad N \\ Zikri ${ }^{3}$ \\ 'Ohio State University, USA \\ ${ }^{2}$ The Wellness Center, USA \\ ${ }^{3}$ Lecturer National Research Center, Egypt
}

Correspondence: Emad N Zikri, Lecturer National Research Center, Cairo, Egypt, Email emadzikri@hotmail.com

Received: February 24, 2018 | Published: March 27, 2018

\section{Introduction}

Osteoarthritis is a common disease that affects the joints leading to erosion of the cartilage. ${ }^{1}$ Its main symptoms are pain, morning stiffness and the reduction of range of flexion and extension of the joint. ${ }^{2} 3.8 \%$ of the population complains of knee osteoarthritis. ${ }^{3}$ knee osteoarthritis is more common in males 45 and younger. Above this age, females are more affected. ${ }^{4}$ It has been proven that the economic impact of knee osteoarthritis is much greater than that of rheumatoid arthritis. ${ }^{5}$ Many conventional medications such as opioid, non-steroidal antiinflammatory drugs and local ointments are available for treatment of osteoarthritis. Local injection of the knee by corticosteroids and hyaluronic acid has been shown to have beneficial effects. However, these medications may have serious hazards. Complementary medicine provides many modalities for the management of knee osteoarthritis. $^{6}$

Aromatherapy is one of the complementary modalities used to manage many diseases. Essential oils are extracted from herbs and exert their therapeutic effect by inhalation or direct contact to the skin. ${ }^{7}$ It had been proved that aromatherapy massage is efficient in improving osteoarthritis pain..$^{8-10}$. Lavender is one of the essential oils applied to relieve muscular and joints pain and reduce inflammation. ${ }^{11}$ It was showen that combining lavender essential oil vapor into the oxygen significantly reduced the amount of pain experienced after surgeries. ${ }^{12}$

\section{Patients and Methods}

\section{Study design}

A case study design.

\section{Inclusion criteria}

a. Grade two knee osteoarthritis diagnosed by plain X-ray and free from any signs of inflammation. b. Intact soft tissue shown by MRI.

c. Overweight or obese patients according to Body Mass index may be included.

d. No medications for knee osteoarthritis taken.

\section{Exclusion criteria}

Diseases that can lead to secondary osteoarthritis (except obesity) such as:
i. Diabetes.
ii. Gout.

iii. Hypothyroidism.

Thirty-two patients (22 females and 10 males) having bilateral grade two knee osteoarthritis were selected from the clinic of the private wellness centre, Columbus, Ohio. Ages ranged between 45 and 76 with a mean age 55.6. Pain intensity on (VAS) visual analog scale, morning stiffness time and tenderness scores were recorded for each patient before the start of a Lavender massage and just after the end of last session.

\section{Pain intensity on (VAS) Visual Analog Scale}

The linear scale is the visual representation of the range of pain that a patient believes he or she might experience. The range is represented by a line, usually $10 \mathrm{~cm}$ in length with or without marks at each centimeter. One end represents "no pain" while the other represents the worst pain the patient could imagine. ${ }^{13}$ A numerical rating scale is a segmented numeric version of the visual analog scale (VAS) in which the patients select the number from $(0-10)$ that best reflects the intensity of pain. ${ }^{14}$ 


\section{Tenderness score}

Tenderness was tested by applying firm pressure to the knee and it was recorded according to the following score.

a. Score 0: The patient feels no pain.

b. Score 1: The patient says it is painful.

c. Score 2: The patient says it is painful and winces.

d. Score 3: The patient says it is painful, winces and withdraws the limb..$^{15}$

This is applied to each of the following sites: suprapatellar, infrapateller, medical collateral ligament, lateral collateral ligament and popliteal fossa, then the mean tenderness score of these areas are calculated. ${ }^{16}$ Tenderness on palpation can be scored on a scale from 0 to 3 where $\mathrm{O}$ represents no pain and 1, 2, 3 represent mild, moderate and severe tenderness respectively. ${ }^{17}$

\section{Radiological examination}

Plain X-ray was performed to verify the degree of knee osteoarthritis. MRI was also done to exclude any defect in soft tissues.

\section{Laboratory methods}

Random blood sugar, uric acid and T.S.H were done for all the patients before the start of the therapy. All the patients included in our study showed normal serum levels for these laboratory parameters.

Each patient was subjected to three sessions of aromatherapy massage per week for four weeks. Each knee was massaged with $5 \mathrm{ml}$. of lavender essential oil for 10 minutes per session. This was performed according to the recommendations of the textbook, "Aromatherapy for health professionals $4^{\text {th }}$ edition 2012"

\section{Statistical method}

Paired T- test used through SPSS program.

\section{Results}

Pain on visual analog scale (VAS) improved significantly in the 32 cases $(100 \%),(\mathrm{P}<0.05)$. Mean of pain score decreased from 7.6 (before the start of lavender sessions) to 2.4 (after the end of lavender sessions) (Table 1). Morning stiffness disappeared in 24 patients $(75 \%)$, its length of time decreased in eight patients $(25 \%)$. The mean of morning stiffness time decreased significantly from 7.1 minutes to 1.2 minutes $(\mathrm{p}<0.05)$ (Table 2). Tenderness disappeared in 28 patients $(87.5 \%)$, while in the remaining four patients $(12.5 \%)$, its level decreased. Mean of tenderness score decreased significantly from 1.43 to $0.162(\mathrm{p}<0.05)$ (Table 3$)$.

Table I Effect of Lavender oil on pain on visual analog scale

\begin{tabular}{lll}
\hline Parameter & $\begin{array}{l}\text { Pretreatment } \\
\text { (Mean } \pm \text { SD) }\end{array}$ & $\begin{array}{l}\text { Post-treatment } \\
\text { (Mean } \pm S D)\end{array}$ \\
\hline Pain score & $7.6 \pm 1.2$ & $2.4^{*} \pm 0.9$
\end{tabular}

$* \mathrm{P}<0.05$

Table 2 Effect of Lavender oil on morning stiffness time

\begin{tabular}{lll}
\hline Parameter & $\begin{array}{l}\text { Pre-treatment } \\
\text { (Mean } \pm \text { SD) }\end{array}$ & $\begin{array}{l}\text { Post-treatment } \\
\text { (Mean } \pm S D)\end{array}$ \\
\hline $\begin{array}{l}\text { Morning stiffness time in } \\
\text { minutes }\end{array}$ & $7.1 \pm 0.75$ & $1.2 * \pm 0.26$ \\
\hline
\end{tabular}

$* \mathrm{P}<0.05$

Table 3 Effect of Lavender oil on tenderness score

\begin{tabular}{lll}
\hline Parameter & $\begin{array}{l}\text { Pre-treatment } \\
\text { (Mean } \pm \text { SD) }\end{array}$ & $\begin{array}{l}\text { Post-treatment } \\
\text { (Mean } \pm \text { SD) }\end{array}$ \\
\hline Tenderness score & $1.43 \pm 0.087$ & $0.162 * \pm 0.065$
\end{tabular}

$* \mathrm{P}<0.05$

\section{Discussion}

Pain on (VAS), morning stiffness and tenderness score were improved significantly in all the cases after the end of the sessions. The essential oils circulated in blood and stimulated the nerve cells to secrete neurotransmitters such as: B- endorphins, enkephalins and serotonin. These have an analgesic effect. ${ }^{18,19}$ Essential oils also decrease serum levels of substance $P$ which is a neuropeptide secreted in the brain and plays a major role in the transmission of pain. ${ }^{20}$ Lavender oil contains linalool and lynalyl acetate. They are photochemicals that reduce pain by preventing muscle spasms..$^{21,22}$

A study performed by Kim et al., ${ }^{23}$ showed that a mixture of lavender, marjoram, eucalyptus, rosemary and peppermint decreased significantly the pain based on VAS and improved the mood of arthritis patients. Another clinical trial done by Jung \& Jeon ${ }^{24}$ proved the efficacy of aroma massage in decreasing the shoulder pain in hemiparesis cases. Essential oils are formed from a blend of lavender, clarysage and bergamot at a ratio of 3:2:1 for 10 minutes three times a week for four weeks. The results achieved by Nasiri et al., ${ }^{25}$ showed that lavender oil massage when used alone improve the pain on VAS in knee osteoarthritis patients. They use $5 \mathrm{ml}$ of the oil for 20 minutes nine times in a three week period.

Another study conducted by $\mathrm{Kim} \& \mathrm{Kim}^{26}$ proved that a massage using lavender, chamomile and ginger oil significantly improved knee osteoarthritis pain. All the results concluded from the previous studies are consistent with our study. We used lavender oil without any essential oils to assess its accurate effect in knee osteoarthritis. This is recommended by the authors of the textbook "Aromatherapy for health professionals $4^{\text {th }}$ edition 2012 and followed through the study done by Nasiri et al., ${ }^{25}$ Unlike other trials, we identified cases diagnosed radiologically with grade two knee osteoarthritis. Our study may be the first one to evaluate morning stiffness time in patients receiving aroma massage. We recommend a greater number of patients be included in further studies. They should be followed after the end of treatment. We may conduct a study containing a placebo group. Laboratory parameters that affect the pain such as: beta- endorphin, encephalin and substance $\mathrm{P}$ can be evaluated to have more objective results.

\section{Conclusion}

Aromatherapy is a safe and cheap tool for reducing the pain of grade two knee osteoarthritis in patients.

\section{Acknowledgments}

None

\section{Conflict of interest}

The authors declare that they have no conflict of interest.

\section{References}


1. Arden N, Blanco F, Cooper C, et al. Atlas of osteoarthritis. Springer: 2015 p. 21.

2. Glyn-Jones S, Palmer AJ, Agricola R, et al. Osteoarthritis. Lancet. 2015;386(9991):376-387.

3. March L, Smith EU, Hoy DG, et al. Burden of disability due to musculoskeletal disorders. Best Pract Res Clin Rheumatol. 2014;28(3):353366.

4. Stephen I Katz. National Institute of Arthritis and musculoskeletal and skin diseases. NIH. 2015;1-49.

5. Lozada CJ, Altman RD. Osteoarthritis. In: Koopman WJ, Boulware D, editors. Clinical primer for Rheumatology. lippincott Williams and Wilkins: Philadelphia; 2003. p. 245-261.

6. Brian M, lixing Lao, Patricia Langenberg. Effectiveness of acupuncture as adjunctive therapy in osteoarthritis of the knee. Ann intern Med. 2004;141(12):901-910.

7. Buckle J. Aromatherapy: Essential oils in Practice. USA: Elsevier Health Sciences; 2014

8. Won SJ, Chae YR. The effects of aromatherapy massage on pain, sleep, and stride length in the elderly with knee osteoarthritis. J Korean Biol Nurs Sci. 2011;13(2):142-148.

9. Choi IR. Effects of aromatherapy massage on pain, physical function, sleep disturbance and depression in elderly women with osteoarthritis. Korean $J$ Women Health Nurs. 2006;12(2):168-176.

10. Kim IJ, Kim EK. Effects of aroma massage on pain, activities of daily living and fatigue in patients with knee osteoarthritis. J Muscle Jt Health. 16(2):145-153.

11. Djenane D, Aïder M, Yangüela J, et al. Antioxidant and antibacterial effects of Lavandula and Mentha essential oils in minced beef inoculated with E. coli O157: $\mathrm{H} 7$ and S. aureus during storage at abuse refrigeration temperature. Meat Sci. 2012;92(4):667-674.

12. WWW.organicfacts

13. Huskisson E. The visual analog scale. In: Melzack R, editor. Pain measurement and assessment. Raven Press: New York; 1983.

14. Johnson C. Measuring pain. Visual analog sacale versus numeric pain scale, what is the difference? J Chiroprac Med. 4(1):43-44.

15. Messier SP, Loeser RF, Miller GD. Exercise and dietary weight loss in overweight and obese older adults with knee osteoarthritis. The arthritis diet and activity promotion trial. Arthritis Rheu. 2004;50(5):1501-1510.

16. Ritchie DM, Boyle JA, MC Innes JM. Clinical studies within articular index for the assessment of joint tenderness in patients with rheumatoid arthritis. QJ Med. 1968;37(147):393-406.

17. Cook JL, Khan KM, Kiss ZS. Reproducibility and clinical utility of tendon palpation to detect patellar tendinopathy in young basketball players. Victorian Institute of sport tendon study group. Br J Sports Med. 2001;35(1):65-69.

18. Kouliv PH, Khaleghi Ghadiri M, Gorji A. Lavender and the nervous system. Evid Based Complement Alternat Med. 2013:681304.

19. Hyldgaard M, Mygind T, Meyer RL. Essential Oils in Food Preservation:Mode of Action, Synergies, and Interactions with Food Matrix Components. Front Microbiol. 2012;3:12

20. Field T, Diego M, Delgado J, et al. Rheumatoid arthritis in upper limbs benefits from moderate pressure massage therapy. Complement Ther Clin Pract. 2013;19(2):101-103.

21. Tillett J, Ames D. The uses of aromatherapy in women's health. J Perinat Neonatal Nurs. 2010;24(3):238-245.

22. Sköld M, Hagvall L, Karlberg AT. Autoxidation of linalyl acetate, the main component of lavender oil, creates potent contact allergens. Contact Dermat. 2008;58(1):9-14.

23. Kim MJ, Nam ES, Palk SI. The effects of aromatherapy on pain, depression and life satisfaction of arthritis patients. Tachan Kanho Hakhoe Chi. 2005;35(1):186-194.

24. Jung HM, Jeon YS. Effects of the aroma massage on shoulder pain, depression, and sleep disturbance in hemiparesis patients. Korean $J$ Rehabil Nurs. 2014;7(2):231-237.

25. Nasiri A, Mahmodi MA, Nobakht Z. Effect of aromatherapy massage with lavender essential oil on pain in patients with osteoarthritis of the knee: A randomized controlled clinical trial. Complement Ther Clin Pract. 2016;25:75-80.

26. Kim IJ, Kim EK. Effects of aroma massage on pain, activities of daily living and fatigue in patients with knee osteoarthritis. $J$ Muscle Jt Health $2009 ; 16(2): 145-153$ 